\title{
Implementasi SCRUM Pada Pengenalan Aksara Lampung Menggunakan Augmented Reality
}

\author{
Ika Arfiani1 1,*, Murien Nugraheni², Danang Sulistyono ${ }^{1}$ \\ ${ }^{1}$ Fakultas Teknologi Industri, Teknik Informatika, Universitas Ahmad Dahlan, Yogyakarta, Indonesia \\ ${ }^{2}$ Fakultas Teknik, Pendidikan Teknik Informatika dan Komputer, Universitas Negeri Jakarta, Jakarta, Indonesia \\ Email: 1,"${ }^{*}$ ka.arfiani@tif.uad.ac.id, ${ }^{2}$ muriennugraheni@unj.ac.id, ${ }^{3}$ danang2604@gmail.com \\ Email Penulis Korespondensi: ika.arfiani@tif.uad.ac.id \\ Submitted: 25/11/2021; Accepted: 28/12/2021; Published: 31/12/2021
}

\begin{abstract}
Abstrak-Provinsi Lampung memiliki 20 Huruf Lampung dan 12 Anak Huruf Lampung sebagai aksara yang perlu dilestarikan. Pembelajaran Aksara Lampung saat ini masih menggunakan metode konvensional sehingga banyak siswa mulai mengabaikan mata pelajaran ini dikarenakan dirasa kurang menarik dan membosankan. Penelitian ini bertujuan untuk membangun aplikasi yang dapat membantu pengguna dalam mengenalkan Aksara Lampung dalam dunia pendidikan pada smartphone dengan menerapkan taknologi Augmented Reality. Dengan menerapkan Marker Based Tracking yang merupakan salah satu metode yang digunakan dalam pengembangan teknologi Augmented Reality. Metode ini bekerja dengan cara mengenali dan mengidentifikasi pola pada marker untuk memunculkan objek virtual ke lingkungan nyata. Pengembangan sistem menggunakan metode waterfall dengan tahapan identifikasi masalah, perencanaan awal, desain dan perancangan, implementasi, uji coba, dan evaluasi. Hasil yang diperoleh berupa aplikasi Augmented Reality mengenalkan Aksara Lampung yang dilengkapi dengan fitur menampilkan 3D, pelafalan satiap objek, galeri aksara, penduan setiap menu, dan 20 marker Aksara Lampung. Pengujian penggunaan teknologi Augmented Reality ini menghasilkan aplikasi Augmented Reality untuk mengenalkan Aksara Lampung yang dilengkapi dengan fitur menampilkan aksara lampung 3D, pelafalan satiap objek Aksara Lampung, galeri aksara, penduan setiap menu dan 20 marker Aksara Lampung. Yang mana jenis kamera smartphone dapat mempengaruhi kemampuan aplikasi dalam melihat objek pada sudut tertentu terhadap marker, namun masih cukup aman pada sudut antara $50^{\circ}$ sampai $180^{\circ}$.
\end{abstract}

Kata Kunci: Aksara Lampung; Android; Augmented Reality; Marker Based Tracking

\begin{abstract}
Lampung Province has 20 Lampung characters and 12 Lampung scripts as characters that need to be preserved. Lampung script learning is currently still using conventional methods so that many students begin to ignore this subject because it feels less interesting and boring. This study aims to build an application that can help users introduce Lampung script in the world of education on smartphones by applying Augmented Reality technology. By applying Marker Based Tracking which is one of the methods used in the development of Augmented Reality technology. This method works by recognizing and identifying patterns on markers to bring up virtual objects into the real environment. The system development uses the waterfall method with the stages of problem identification, initial planning, design and design, implementation, testing, and evaluation. This results in an Augmented Reality application to introduce Lampung script which is equipped with features showing 3D Lampung script, pronunciation of each Lampung script object, script gallery, guide for each menu and 20 Lampung script markers. Which type of smartphone camera can affect the application's ability to see objects at a certain angle to the marker, but is still quite safe at angles between $50^{\circ}$ to $180^{\circ}$.
\end{abstract}

Keywords: Lampung Script; Android; Augmented Reality; Marker Based Tracking

\section{PENDAHULUAN}

Indonesia memiliki banyak aneka suku yang memiliki kebudayaan, adat istiadat dan pandangan berbeda-beda yang tersebar di seluruh Nusantara [1]. Lampung merupakan salah satu provinsi yang memiliki aneka ragam budaya dan bahasa [2]. Aksara Lampung salah satu bagian budaya yang dimiliki oleh bangsa Indonesia, bermacam-macam aksara yang keberadaannya memiliki peranan penting sebagai identitas dalam daerahnya masing-masing. Tulisan merupakan salah satu alat untuk merekam perubahan jaman [3]. Sehingga banyak desainer typeface yang merekam berbagai macam budaya dan mengubahnya ke dalam typeface [4]. Aksara Lampung atau Had Lampung lahir pada awal abad ke-9 [5].

Pelestarian aksara merupakan sebuah tugas yang harus dilakukan oleh masyarakat Indonesia terutama pada daerah yang memiliki aksara, sekarang ini masyarakat Provinsi Lampung mulai jarang menggunakan bahasa dan aksara Lampung sebagai sarana berkomunikasi sehari-hari, di karenakan persebaran penduduk di provinsi Lampung tidak lagi didominasi oleh suku Lampung. Masyarakat yang bersuku Lampung hanya 11,92\% di provinsi Lampung selebihnya banyak pendatang dari luar Provinsi Lampung yang tinggal dan menetap di wilayah Provinsi Lampung.[6] Untuk mengatasi masalah tersebut Provinsi Lampung sudah berupaya dalam melestarikan Aksara Lampung melalui mata pelajaran muatan lokal yang di berikan kepada Sekolah Tingkat Dasar (SD) dan Tingkat Menengah Pertama (SMP), dalam pembelajaran aksara lampung saat ini masih menggunakan metode konvensional, membuat banyak siswa mulai mengabaikan mata pelajaran ini dikarenakan Aksara Lampung kurang menarik dan mulai membosankan. Oleh karena itu diperlukan upaya lain yang dapat dilakukan untuk mengatasi permasalahan ini, agar Aksara Lampung bisa di lestarikan dan di pelajari secara mudah dan menarik. Salah satu cara yaitu dengan memanfaatkan Implementasi Teknologi Augmented Reality Media Pengenalan Aksara Lampung Berbasis Mobile sebagai media pembejaran, teknologi ini di harapkan mampu membangun minat siswa dalam mempelajari aksara lampung, baik Siswa Tingkat Dasar (SD) dan Siswa Tingkat Pertama (SMP) dapat menggunakannya sebagai media proses pembelajaran seharihari. 
Inovasi dengan memanfaatkan Teknologi Infomasi (TI) ke dalam dunia pendidikan perlu dilakukan demi mempermudah tingkat pemahaman seseorang dalam memahami sebuah informasi. Penggunaan teknologi yang berkembang saat ini merupakan salah satu kebutuhan manusia dalam mengakses informasi secara cepat dan mudah dilakukan. Perkembangan teknologi yang begitu pesat ini dan trend teknologi adalah aplikasi berbasis mobile yang diterapkan dalam sistem operasi yang banyak penggunanya yaitu Android. Pada aplikasi yang berbasis android, terus dilakukan perkembangan seperti penggabungan dunia nyata dan virtual atau yang lebih dikenal dengan teknologi augmented reality. VR (Virtual Reality) dan AR (Augmented Reality) adalah teknologi yang konsepnya telah diperkenalkan sejak lama. Teknologi ini membuat kita dapat merasakan berada di dalam computer generated environment atau mengakses berbagai data seperti video, gambar, suara, grafik, bahkan data GPS. Dengan teknologi ini memungkinkan pengguna dapat merasakan seakan berada di tempat lain atau berada di dalam sebuah film yang sedang dilihat. Ada juga yang mengemukakan bahwa Augmented Reality merupakan metafora baru dalam teknologi interaksi manusia dan komputer [7].

Proses pembelajaran pada umumnya dapat lebih mudah diterapkan dengan menggunakan bantuan teknologi, karena pengguna akan lebih mudah memahami maupun mengenal Aksara Lampung dengan dilengkapi sebuah objek animasi 3D melalui sebuah aplikasi berbasis Augmented Reality (AR). Pada penelitian ini bertujuan untuk memanfaatkan teknologi augmented reality dengan menerapkan unsur multimedia sebagai media pengenalan Aksara Lampung pada sistem operasi Android. Adapun teknik yang digunakan dalam teknologi augmented reality adalah menggunakan Metode Marker Based Tracking.

Marker Based Tracking adalah salah satu metode yang dapat digunakan dalam pengembangan teknologi augmented reality. Metode ini bekerja dengan cara mengenali dan mengidentifikasi pola pada sebuah marker untuk memunculkan sebuah objek virtual ke lingkungan nyata. Marker adalah sebuah pola berbentuk persegi berwarna hitam putih dengan sisi tebal berwarna hitam[8].

\section{METODOLOGI PENELITIAN}

\subsection{Tahapan Penelitian}

Penelitian ini dikembangkan berdasar pada metode Research and Development (R\&D). Metode ini dapat digunakan dalam berbagai bidang dan disiplin ilmu. Semuanya bisa mengembangkan tahapan dan proses R\&D yang berbeda terkait dengan ciri khas bidangnya masing -masing. Tidak terkecuali dengan bidang teknologi yang berkaitan dengan pendidikan. [9]. Oleh karena itu dalam pengembangan media pembelajaran ini digunakan metode pengembangan software SCRUM. SCRUM adalah salah satu framework yang bersifat agile untuk pengembangan perangkat lunak yang adaptif dan menghasilkan perangkat lunak sesuai kebutuhan pengguna [10].

Metode Scrum seperti Gambar 1 menerapkan key practices yang digunakan sebgai acuan yakni berpegang pada agenda jadwal, bekerja konsisten sesuai sprint, product backlog merupakan tanda dalam pekerjaan, produk backlog dasar melakukan sprint dan tim harus memutuskan produk dapat dikembangkan atau tidak, SCRUM master bertanggung jawab menerima hasil sprint, mengadakan meeting setiap hari kerja, dan berfokus pada sprint, meeting, review dan project timeline [11].

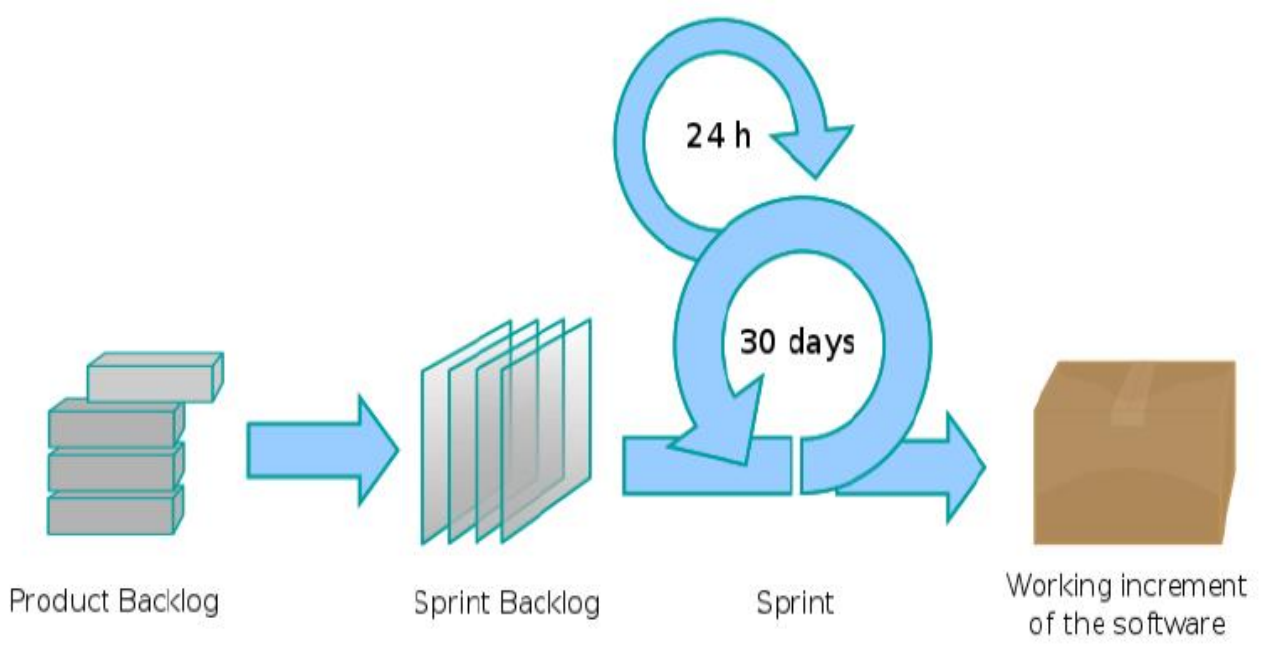

Gambar 1. Proses Pengembangan Scrum [6]

Pada Gambar 1 terlihat proses pengembangan menggunakan Scrum yang mana setiap atahapannya dapat dijelaskan sebagai berikut :

\section{Product backlog}

Product backlog ialah tahap pengumpulan kebutuhan software yang akan dikembangkan dengan cara membuat daftar kebutuhan [13]. Product backlog berisi backlog item yang dibuat berdasarkan requirements yang didapat 
dari pengumpulan data melalui wawancara serta fokus grup diskusi kepada para siswa, orangtua, dan guru terkait bagaimana proses pembelajaran aksara Lampung saat ini serta kemudahan akses literasi pendukungnya. Requirements pada product backlog bersifat dinamis sehingga akan terus menerus bertambah apabila mendapatkan feedback dari pengguna pada saat review dan demo aplikasi. [14]

\section{Sprint backlog}

Sprint backlog ialah tahap pemenuhan dari kebutuhan yang telah dibuat pada daftar product backlog[15]. Atau daftar product backlog item yang terpilih dan terurut berdasarkan prioritasnya untuk dikerjakan dalam sprint dengan perencanaan dan perkiraan mengenai fungsionalitasnya untuk menghasilkan produk yang diinginkan [16]. Dari daftar yang ada maka kebutuhan softaware ini adalah bagaimana menampilkan bentuk 3D dari seluruh aksara lampung dengan cara melakukan scan kartu yang telah dibuat untuk selanjutnya nanti model yang muncul dapat diputar sesuai dengan keinginan pengguna guna melihat bentuk 3D dari seluruh sisi. Sekaligus mampu mengeluarkan suara cara membaca aksara Lampung tersebut. Maka pekerjaan yang dilakukan membuat desain marker, desain model 3D aksara Lampung, desain menu aplikasi, proses pemrograman/coding aplikasi, sampai build aplikasinya. Dimana proses tracking marker seperti Gambar 2.

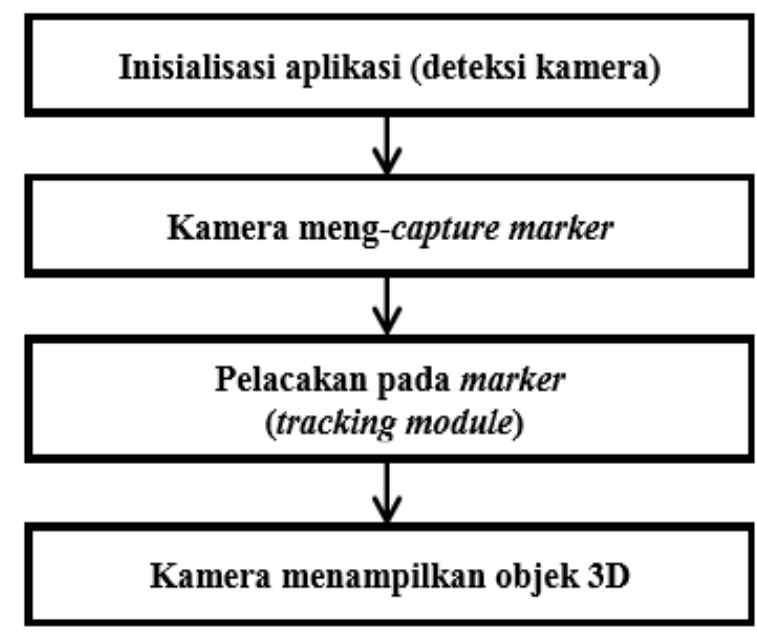

Gambar 2. Alur model Marker based tracking

\section{Sprint}

Sprint ialah tahap dilakukanmya pemaparan hasil produk dalam bentuk prototype kepada para guru yang mengajar materi aksara Lampung. Pada fase ini juga dilakukan pemaparan terkait bagaimana cara menggunakan aplikasi mulai dari persispan sampai bagaimana software dijalankan oleh pengguna akhir (client).

4. Peningkatan kerja software

Pada tahapan ini dilakukan penyempurnaan kerja dari hasil sprint yang telah dilakukan dengan cara menerima umpan balik dari pihak-pihak yang terkait untuk selanjutnya dilakukan perbaikan software secara iterative hingga aplikasi selesai dan siap digunakan

\section{HASIL DAN PEMBAHASAN}

\subsection{Produk Backlog}

Product backlog yang teah dihasilkan tampak seperti dalam Tabel 1. Dimana muncul tujuh item yang siap untuk diimplementasikan.

Tabel 1. Product Backlog Aplikasi AR Aksara Lampung

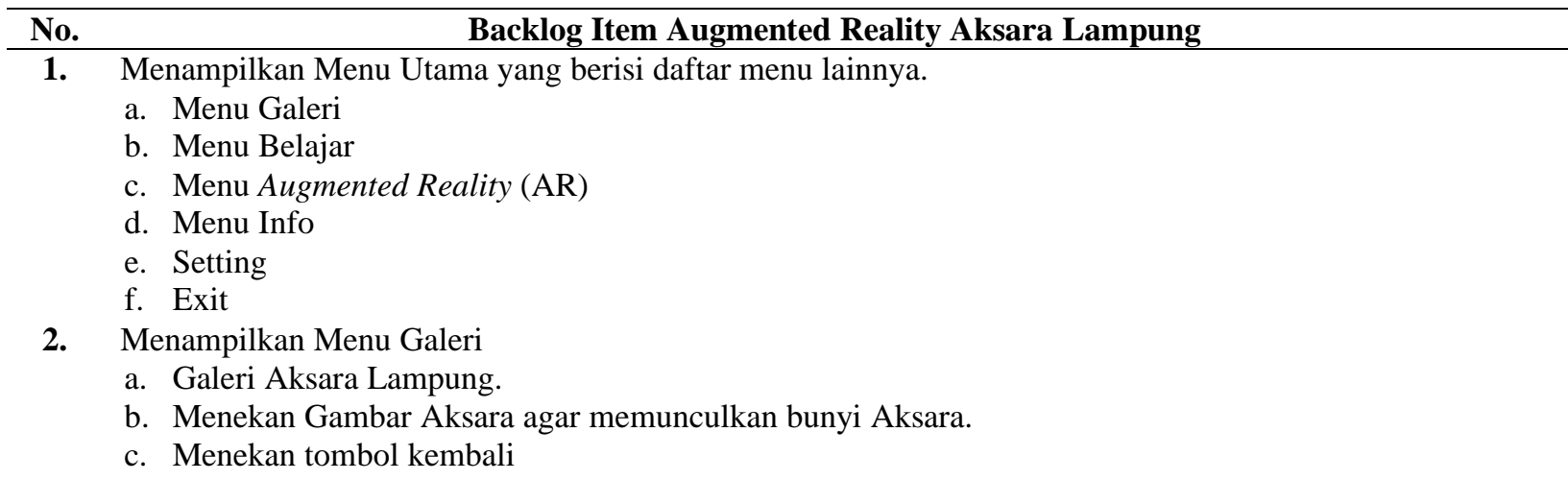


3. Menampilkan Menu Belajar

a. Menampilkan Setiap Aksara Lampung dalam bentuk 2D.

b. Menekan tombol panah kanan atau kiri akan berganti dengan aksara lain dengan bunyi suara di setiap tombol panah di tekan.

c. Menekan tombol back.

4. Menampilkan Menu Augmented Reality (AR).
a. Menampilkan kamera Scan.
b. Memperbesar dan mengecilkan huruf aksara lampung
c. Menekan tombol back

5. Menampilkan Menu info
a. Menampilkan Informasi menu Aplikasi Aksara Lampung.

6. Menampilkan Menu Setting

a. Menampilkan On Off Musik.

7. Menampilkan Jendela keluar Aplikasi dan keluar dari Aplikasi.

\subsection{Sprint Backlog}

Setelah pengumpulan data selesai maka selanjutnya ke tahap pembuatan desain marker, desain aksara lampung dan desain tampilan menu aplikasi, sebagai gambaran untuk melakukan pembuatan Aplikasi Augmented Reality Aksara Lampung Berbasis Mobile. Tahap ini di lakukan untuk membuat marker sebagai alas untuk mampilkan objek aksara lampung 3D yang terdiri dari 20 marker yang berbeda, setiap marker akan di sesuaikan dengan objek 3D yang akan di tampilkan, desain marker seperti pada Gambar 3.

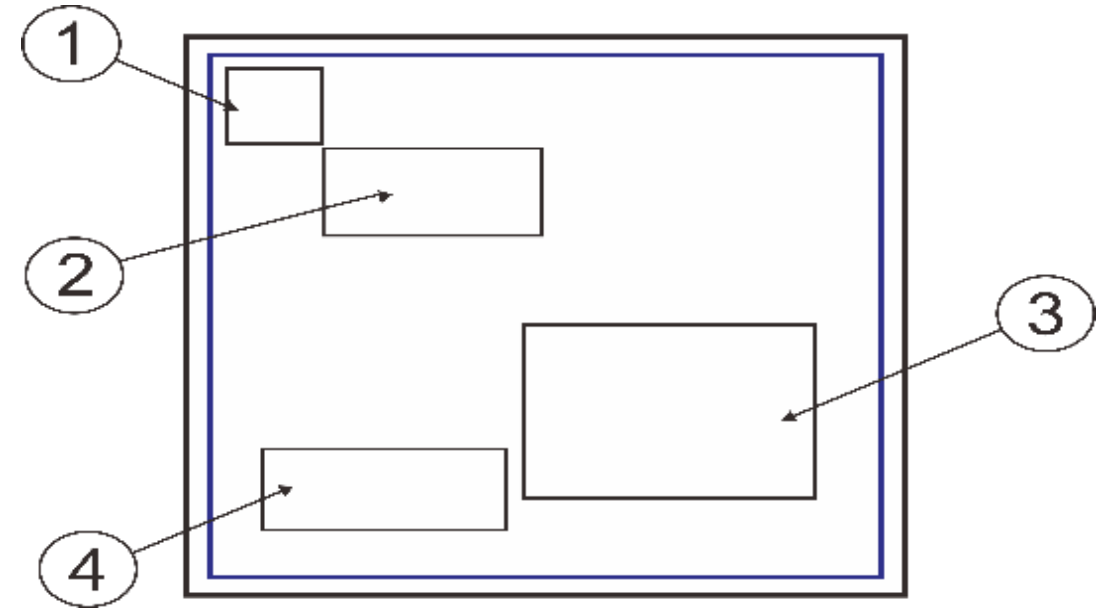

Gambar 3. Desain Marker Aksara

Keterangan:

1. Nama Aksara Lampung

2. Bentuk Aksara Lampung

3. Gambar

4. Nama Gambar

Hasil marker yang telah dibuat terlihat pada Gambar 4. Dimana marker ini dicetak dalam sebuah kartu yang nantinya siap untuk dipindai dengan kamera agar terlihat bentuk 3D dari bentuk aksara Lampungnya.

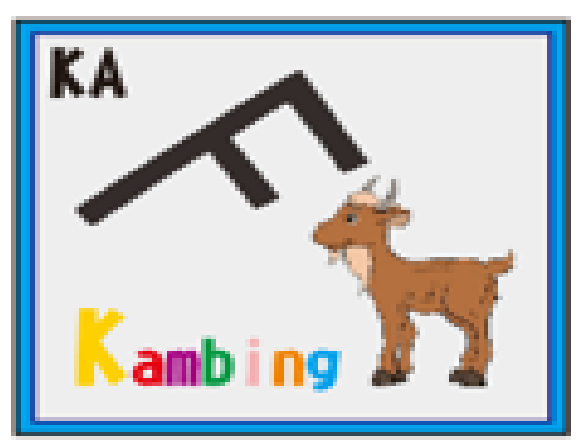

Gambar 4. Desain Marker Aksara

Setelah mendesain marker selanjutnya membuat setiap karakter aksara lampung ke dalam bentuk 3D menggunakan Software Blander seperti Gambar 5. 
Building of Informatics, Technology and Science (BITS)

Volume 3, No 3, Desember 2021 Page: 353-360

ISSN 2684-8910 (media cetak)

ISSN 2685-3310 (media online)

DOI 10.47065/bits.v3i3.1077

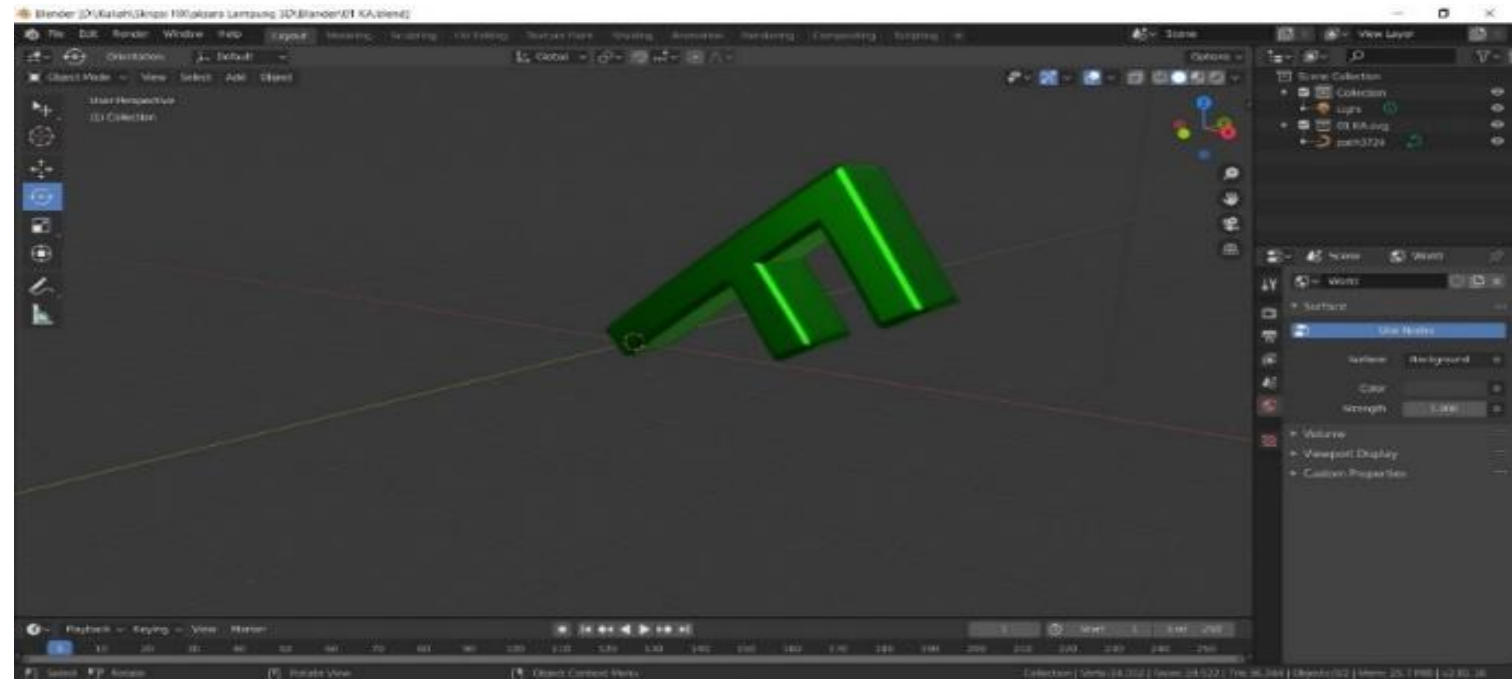

Gambar 5. Desain Aksara Lampung 3D

Tahapan selanjutnya adalah recording audio untuk pelafalan setiap karakter hurufnya dan pemrograman AR nya ke dalam software Unity.Tahapan implementasi AR dapat dilihat pada Gambar 6.

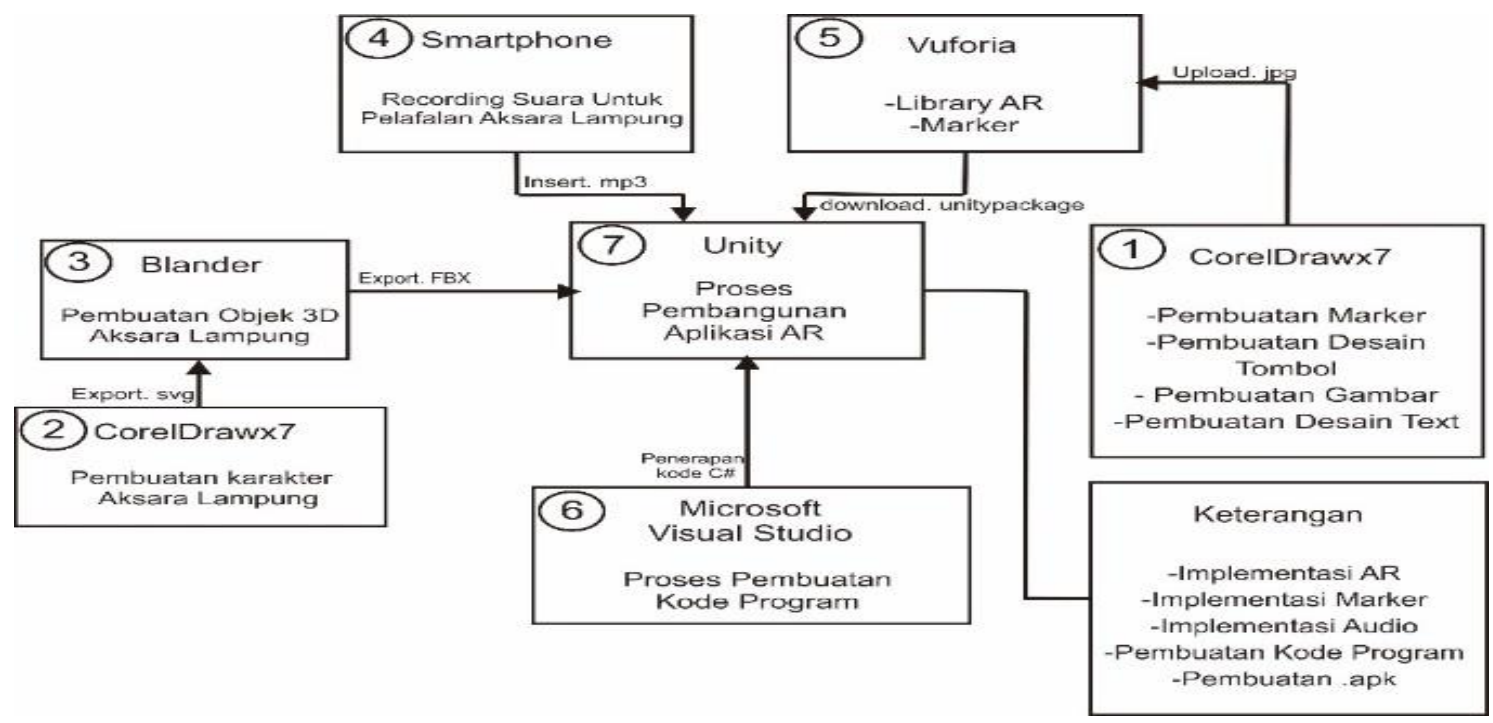

Gambar 6. Proses Implementasi AR

Proses Tata letak di lakukan agar objek dengan marker dapat sesuai dan menampilkan objek 3D dengan sempurna. Objek 3D dengan marker dapat dilihat pada Gambar 7.

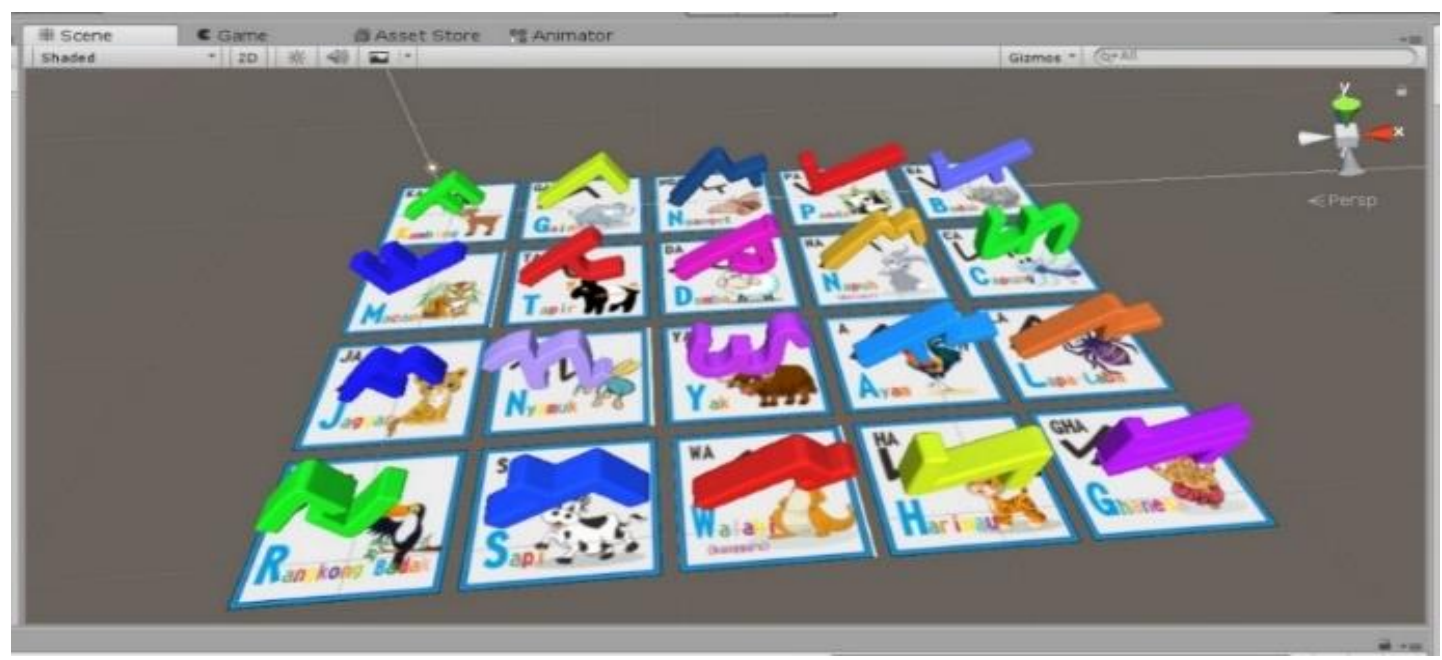

Gambar 7. Tata letak Karakter Aksara 3D di unity 


\subsection{Sprint}

Setelah proses pembuatan program selesai maka aplikasi akan dieksport menjadi aplikasi Android sehingga aplikasi dapat instal dan dijalankan pada smartphone. Hasil implementasi dari sprint backlog ini berupa aplikasi AR aksara Lampung yang diujikan ke sample user dengan berbagai pertanyaan dalam bentuk questioner pengujian.

\section{Tampilan Menu Utama}

Menu Utama merupakan menu yang muncul setelah menekan tombol ketuk pada loading screen. Menu utama berisi beberapa menu diantaranya menu Galeri, menu Scan AR, menu Belajar, menu info, pengaturan dan tombol keluar. Tampilan menu utama pada aplikasi dapat dilihat pada gambar 8 .

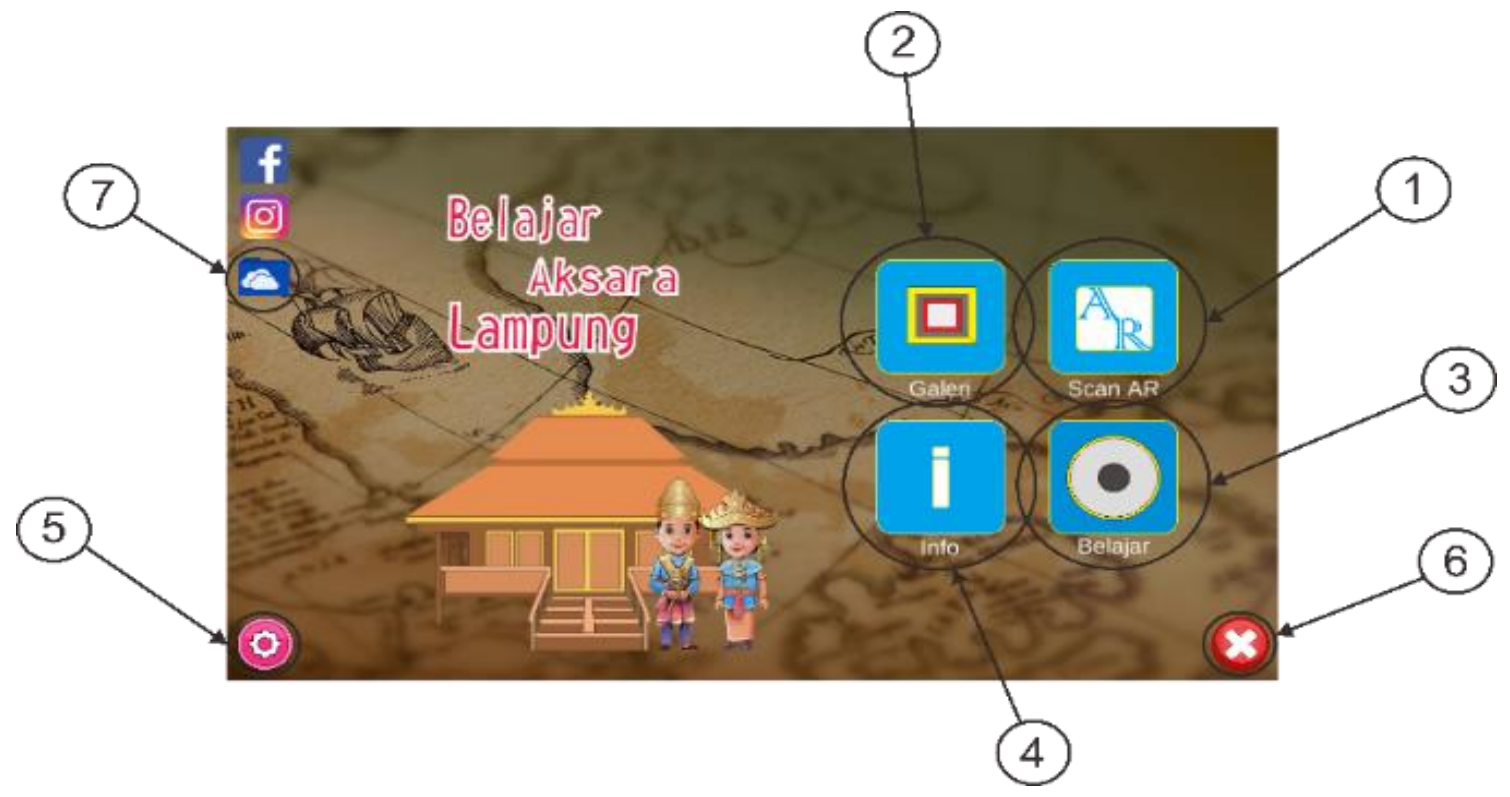

Gambar 8. Menu Utama

1) Button scan AR Aksara Lampung berfungsi untuk mengakses ke menu Augmented Reality.

2) Button Galeri berfungsi untuk mengakses menu Galeri untuk menjalankan Galeri.

3) Button Belajar berfungsi untuk mengakses menu Belajar dan untuk menjalankan menu Belajar.

4) Button Info berfungsi untuk mengakses menu info yang menampilkan penjelasan aplikasi AR lampung.

5) Button Setting berfungsi untuk mengakses menu setting yang menampilkan button on/off musik.

6) Button Keluar berfungsi untuk keluar Aplikasi AR Aksara Lampung Augmented Reality.

7) Button Drive bersungsi untuk mengakses marker aksara.

\section{Tampilan Scan Marker}

Hasil pengujian pada marker berhasil menampilkan objek 3D aksara lampung proses pemindaian aksara lampung 3D sesuai antara marker dan objek aksara lampung 3D sama. Objek 3D aksara lampung akan muncul pada saat pemindaian marker di lakukan. Hasil pengujian marker yang terdeteksi dapat dilihat pada Gambar 9.

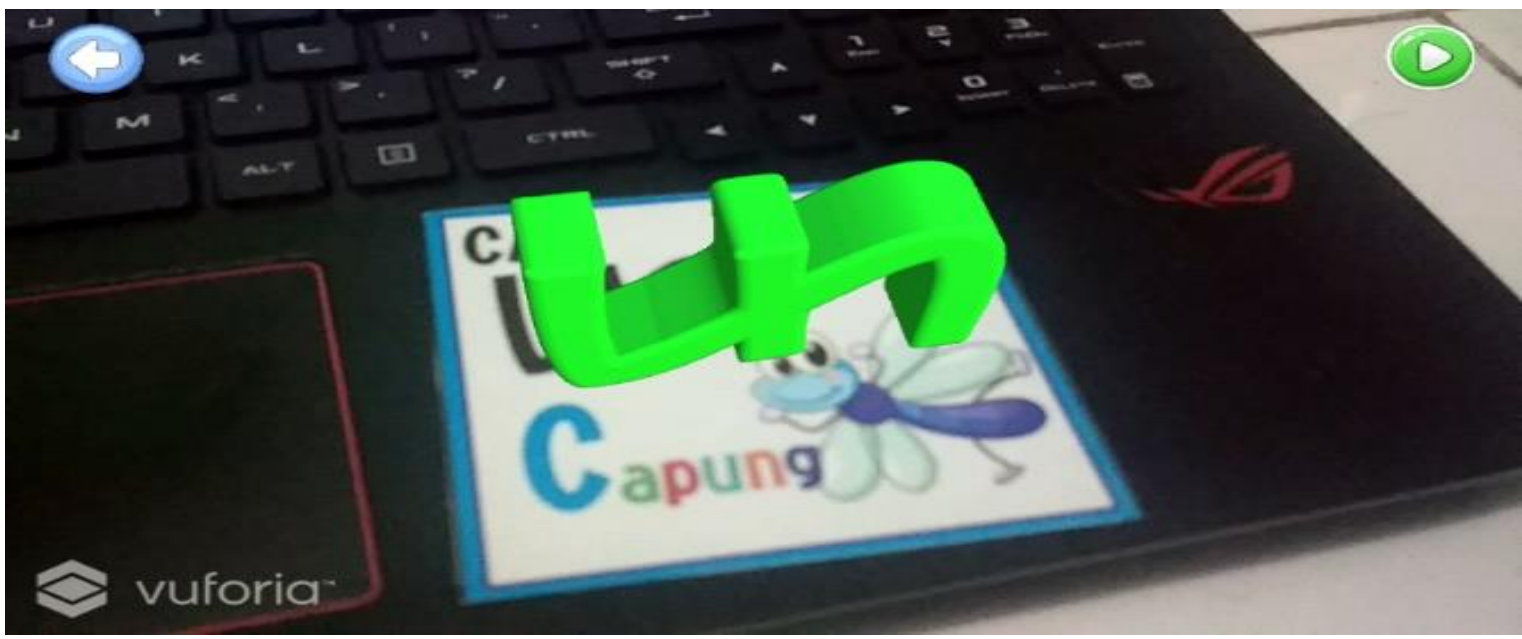

Gambar 9. Hasil pengujian Scan Augmented Reality (AR) 
Building of Informatics, Technology and Science (BITS)

Volume 3, No 3, Desember 2021 Page: 353-360

ISSN 2684-8910 (media cetak)

ISSN 2685-3310 (media online)

DOI 10.47065/bits.v3i3.1077

\section{Tampilan Menu Galeri}

Menu galeri berfungsi untuk menampilkan keseluruhan bentuk aksara lampung dan menampilkan cara membaca aksara lampung tersebut. Tampilan Menu Galeri dapat di lihat pada gambar 10 .

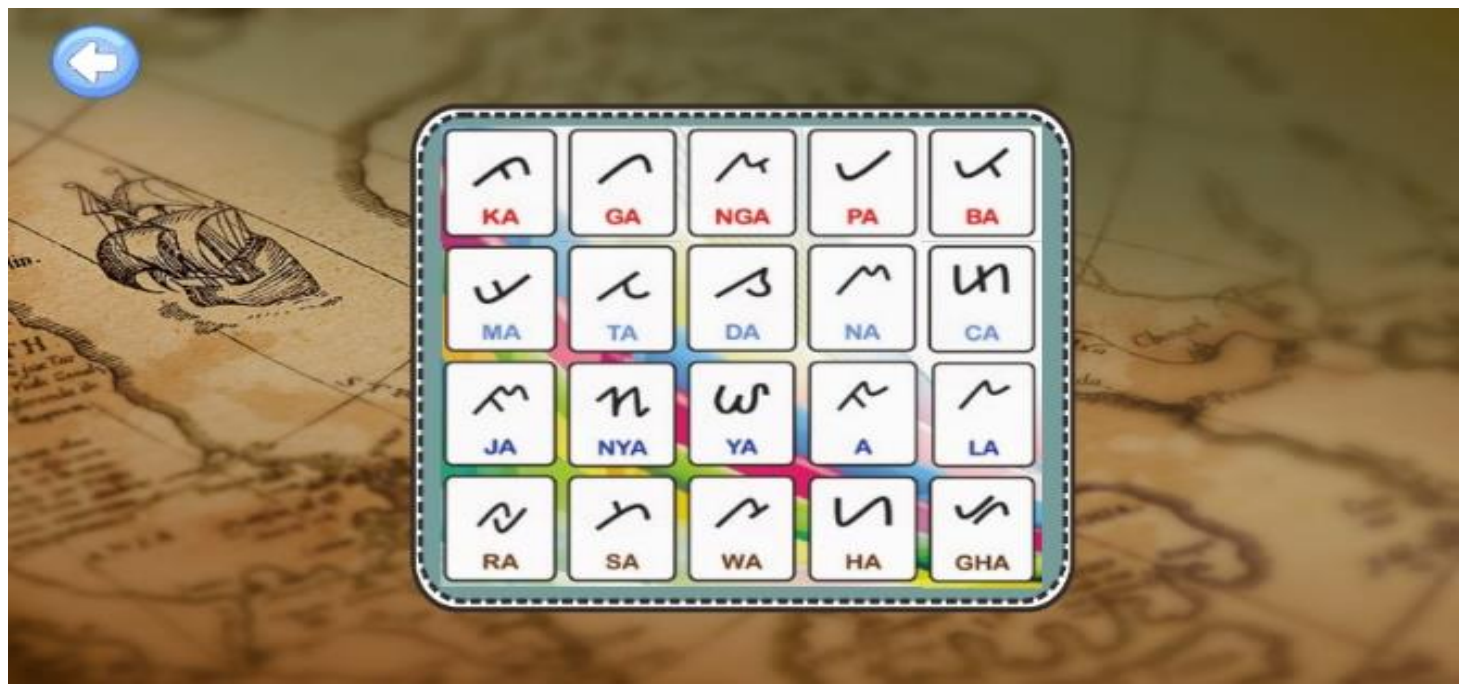

Gambar 10. Tampilan Menu Galeri

\section{Tampilan Menu Belajar}

Menu belajar berfungsi untuk menampilkan satu persatu aksara lampung, cara membaca aksara lampung dengan suara Audio aksra lampung di setiap kali di pindah ke aksara lampung lainnya. Tampilan menu belajar dapat di lihat pada gambar 11 .

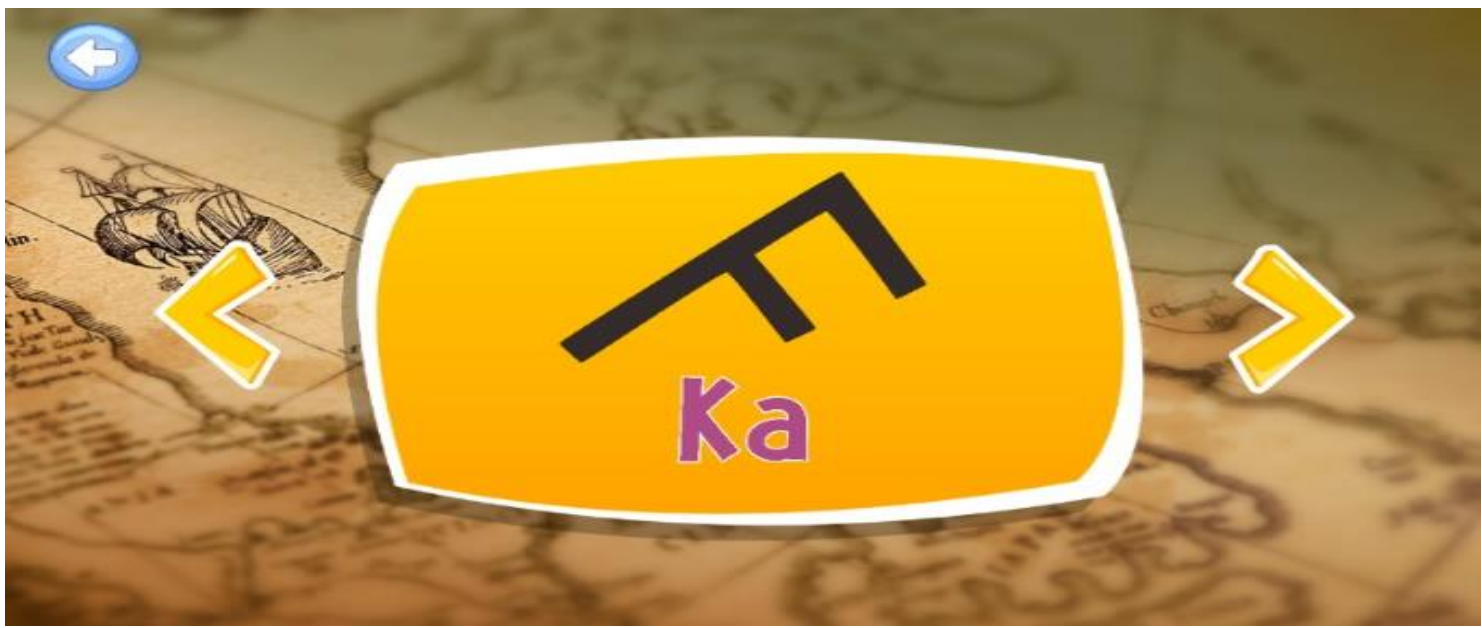

Gambar 11. Tampilan Menu Belajar

Bersamaan dengan sprint, sebelum diujikan ke user maka dilakukan pengujian Sudut. Pengujian sudut ini dilakukan untuk mengetahui sudut berapa saja yang dapat mendeteksi marker, agar dapat menampilkan objek AR 3D Aksara Lampung. Pengujian ini menggunakan tiga Smartphone yang berbeda merk dan berbeda kamera. Untuk tabel hasil pengujian dapat dilihat pada Tabel 2.

Tabel 2. Hasil Pengujian Sudut Aplikasi AR

\begin{tabular}{|c|c|c|c|c|c|c|c|c|}
\hline \multirow{2}{*}{ No } & \multirow{2}{*}{ Merek HP } & \multirow{2}{*}{ Spesifikasi Mobile } & \multicolumn{6}{|c|}{ Sudut (Derajat) } \\
\hline & & & $180^{0}$ & $90^{\circ}$ & $80^{\circ}$ & $70^{0}$ & $60^{0}$ & $50^{0}$ \\
\hline 1 & OPPO F5 & $\begin{array}{l}\text { 1. Kamera Single } 16 \mathrm{Mp} \\
\text { 2. Platform OS Androit } 7.1 .1 \text { (Nougat). }\end{array}$ & ya & ya & ya & ya & ya & ya \\
\hline 2 & $\begin{array}{l}\text { Xiaomi Redmi } \\
\text { Note } 8\end{array}$ & $\begin{array}{l}\text { 1. Kamera } 48 \mathrm{MP}, \mathrm{f} / 1.8,26 \mathrm{~mm} \text { (wide), } 12.0 \text {, } \\
\text { 0.8um, PDAF } \\
\text { 2. Platform Android } 9.0 \text { (Pie); MIUI } 11\end{array}$ & ya & ya & ya & ya & ya & ya \\
\hline 3 & Xiaomi 4x & $\begin{array}{l}\text { 1. Kamera } 13 \mathrm{MP}, \mathrm{f} / 2.0 \text {, phase detection } \\
\text { autifokus, LED Flash } \\
\text { 2. Platform MIUI } 8 \text { With Android 6.0.1 } \\
\text { (Marshmallow) }\end{array}$ & ya & ya & ya & ya & ya & ya \\
\hline
\end{tabular}




\section{KESIMPULAN}

Penelitian ini telah menghasilkan aplikasi Augmented Reality untuk mengenalkan Aksara Lampung yang dilengkapi dengan fitur menampilkan aksara lampung 3D, pelafalan satiap objek Aksara Lampung, galeri aksara, penduan setiap menu dan 20 marker Aksara Lampung. Yang mana jenis kamera smartphone dapat mempengaruhi kemampuan aplikasi dalam melihat objek pada sudut tertentu terhadap marker, namun masih cukup aman pada sudut antara $50^{\circ}$ sampai $180^{\circ}$.

\section{REFERENCES}

[1] Melissa, N. 2015. Menilik kekayaan dan keragaman Indonesia. Diperoleh dari website https://www.inmetmining.com/menilik-kekayaan-dan-keragamanindonesia/.

[2] Ediyansyah, R. 2019. Uniknya suku Lampung saibatin dan pepadun serta subsuku didalamnya. Diperoleh dari website https://www.lampung.co/blog/uniknya-suku-lampung-saibatin-danpepadun-serta-sub-suku-didalamnya/.

[3] Budiono, P. 2017. Menulis, merekam sejarah. Diperoleh dari website https://www.kompasiana.com/gunawanbp/5978da417460f051a30da922/m enulis-merekam-sejarah.

[4] Willen, B. \& Strals, N. 2019. Lettering \& type: creating letters and designing typefaces. New York: Princeton Achitectural Press.

[5] Galandi, F. 2016. Artikel ilmiah aksara Lampung. Diperoleh dari website http://www.pengetahuandanteknologi.com/2016/09/artikel-ilmiah-aksaralampung.html

[6] Kantor Bahasa Provinsi Lampung. 2008. Persebaran Bahasa-Bahasa di Provinsi Lampung. Bandar Lampung: Kantor Bahasa Provinsi Lampung

[7] Azuma, R T. 1997. “ $\{A\}\{$ S $\}$ urvey of $\{A\}$ ugmented $\{$ R $\}$ eality.” Presence: Teleoperators and Virtual Environments 6(4): 355-85

[8] Bangor, Aaron et al. 2009. "Determining What Individual SUS Scores Mean : Adding an Adjective Rating Scale.” 4(3): 11423

[9] Sugiyono. 2009. Metode Penelitian Kuantitatif, Kualitatif, dan R \& D. Bandung: Alfabeta.

[10] R. Hundhausen, Professional Scrum Development with Microsoft ${ }^{\circledR}$ Visual Studio® 2012, 1st Ed. Washington: Microsoft Press, 2012

[11] R. S. Kenett and E. Baker, 2010. Process improvement and CMMI for systems and software. CRC Press.

[12] R. S. Kenett, 2013. "Implementing SCRUM using business process management and pattern analysis methodologies," Dyn. Relationships Manag. J., vol. 2, no. 2, pp. 29-48.

[13] T. Bratakusuma, 2019. "Sistem Informasi Eksekutif Sebagai Pendukung Penganggaran Di Pemerintah Desa Melalui Integrasi Sistem Dengan Teknologi Web Service Dan Aplikasi Seluler (STUDI KASUS DESA DERMAJI)," J. Teknol. dan Terap. Bisnis, vol. 2, no. 2, pp. 9-16.

[14] Nurzaman,F. 2020. "Pengembangan Sistem Otomatisasi Tagihan Menggunakan Metode Agile Software Development." J. IKRA-ITH Informatika Vol 4 No 1, pp. 46-57.

[15] S. Sauda, N. Oktaviani, and M. Bunyamin, 2019. "Implementasi Metode Scrum Dalam Pengembangan Test Engine Try Out Sertifikasi," JISKA (Jurnal Inform. Sunan Kalijaga), vol. 3, no. 3, pp. 70-78.

[16] Schwaber, K., \& Jeff, S. (2013). Panduan Scrum TM, (November). 